\title{
Sickle cell disease in children: chronic complications and search of predictive factors for adverse outcomes
}

\author{
Inês Vaz Silva ${ }^{1, *}$, Ana Filipa Reis ${ }^{2}$, Maria João Palaré ${ }^{3}$, Anabela Ferrão ${ }^{3}$, Teresa Rodrigues ${ }^{4}$, Anabela \\ Morais $^{3}$ \\ ${ }^{1}$ Department of Paediatrics, Hospital Vila Franca de Xira, Vila Franca de Xira; ${ }^{2}$ Department of Paediatrics, Hospital Garcia de Orta, Almada; ${ }^{3}$ Unit \\ of Paediatric Haematology, Department of Paediatrics, Hospital de Santa Maria, Centro Hospitalar Lisboa Norte, EPE, Lisboa; ${ }^{4}$ Laboratory of \\ Biomathematics, Faculdade de Medicina de Lisboa, Lisboa, Portugal
}

\begin{abstract}
Background: Sickle cell disease (SCD) has extremely variable phenotypes, and several factors have been associated with the severity of the disease. Objectives: To analyze the chronic complications of SCD and look for predictive risk factors for increased severity and number of complications. Methods: Retrospective study including all children followed for SCD in the Paediatric Haematology Unit of a tertiary hospital in Portugal, who completed $17 \mathrm{yr}$ old between the years 2004 and 2013. Results: We identified 44 patients, 55\% female and $98 \%$ black. Chronic complications occurred in $80 \%$ of cases. Slight dilatation of the left ventricle was the most frequent complication $(47.7 \%)$, followed by respiratory function disturbs $(43.2 \%)$, microlithiasis or cholelithiasis $(40.9 \%)$, increased flow velocity of cerebral arteries (31.8\%), enuresis, delayed puberty and bone abnormalities (6.8\% each), sickle cell retinopathy and leg ulcer (4.6\% each) and recurrent priapism (2.3\%). We identified a statistically significant association between leukocytes $>15000 / \mu \mathrm{L}$ and a higher number of hospitalizations $(P<0.001)$ and chronic complications of the disease $(P=0.035)$. The occurrence of dactylitis in first year of life was also significantly associated with a higher number of hospitalizations $(P=0.004)$ and chronic complications $(P=0.018)$. The presence of $\alpha$-thalassemia was associated with a lower number of chronic complications $(P=0.036)$. Conclusions: Leucocytosis and dactylitis in the first year of life can be predictors of SCD severity, while the presence of $\alpha$-thalassemia can be protective. The determination of early predictors of chronic complications of SCD may improve the comprehensive care of these patients.
\end{abstract}

Key words sickle cell disease; chronic complications; dactylitis

Correspondence Inês Vaz Silva, Serviço de Pediatria, Hospital de Vila Franca de Xira - Rua do Parque Residencial dos Povos, $2600-$ 009 Vila Franca de Xira, Portugal. Tel: +351 263006 500; Fax: +351 263006 501; e-mail: inesvazsilva83@gmail.com

*Present address:Hospital de Vila Franca de Xira - Rua do Parque Residencial dos Povos, 2600-009, Vila Franca de Xira, Portugal

Sickle cell disease (SCD) is a chronic anemia characterized by a homozygote mutation in the $\beta$-hemoglobin gene. The prevalence of SCD in Europe is about 15 cases per 100000 inhabitants (1).

Sickle cell disease has extremely variable phenotypes. Some patients have a mild disease that can be clinically unapparent, while others can be affected by most of its severe complications (2). Therefore, understanding the relationship between clinical and laboratory parameters of SCD may be useful in predicting the severity of disease and the risk of early death (2). This would not only allow a risk-based counseling for families but also justify the early use of disease-modifying or curative interventions, such as hydroxyurea, chronic transfusions, or stem-cell transplantation (3).

Various factors have been found to modulate sickle cell disease (4). A low level of fetal hemoglobin $(\mathrm{HbF})(4,5)$, a low level of total hemoglobin $(5,6)$, and an increased base-line white-cell count $(2,6)$ above $15000 / \mathrm{mm}^{3}$ were associated 
with disease severity and increased risk of death (5). The recommended level of $\mathrm{HbF}$ in these patients is not consensual in the literature (4). However, levels of $\mathrm{HbF}$ above $5.4 \%$ have been associated with a risk reduction in early onset of dactylitis, pain crises, acute chest syndrome, and acute splenic sequestration, while levels above $10 \%$ were associated with fewer chronic leg ulcers in children (4). Clinical severity of disease is also influenced by the presence of $\alpha$-thalassemia (2, 4 ) and by the haplotype linked to the $\beta$-globin gene (4). On the other hand, some authors have demonstrated that children who experienced dactylitis in the first year of life are more likely to have adverse outcomes in later childhood $(3,6,7)$.

The purpose of this study was (i) to characterize the chronic complications of SCD in our patients and (ii) to analyze the association between the presence of previously described severity risk factors and the number of hospitalizations and chronic complications.

\section{Materials and methods}

A retrospective study was performed including all children followed in the Unit of Paediatric Haematology of Hospital de Santa Maria (UHP-HSM) for SCD, who completed $17 \mathrm{yr}$ between the years 2004 and 2013. Clinical data were collected from patients' clinical notes. SCD diagnosis was established through hemoglobin electrophoresis in all patients, associated to isoelectric focusing of the hemoglobin technique or cation-exchange high-performance liquid chromatography. The steady-state leukocyte count and hemoglobin level were calculated through the mean of three values obtained after the first year of life, in the absence of acute illness. The value of $\mathrm{HbF}$ level used in this series was the first obtained after the first year of life, (determined with Betke's method). Alpha-thalassemia was diagnosed through polymerase chain reaction (PCR) detection of $-\alpha 3.7$ and $-\alpha 4.2$ deletions in the genes encoding alpha globin chain. These mutations correspond to more than $95 \%$ of $\alpha$-thalassemia cases in the Portuguese population. Cardiac ejection fraction was considered reduced when inferior to $55 \%$. Obstructive lung defect was defined as a forced expiratory volume in the first second (FEV1)/forced vital capacity (FVC) $<80 \%$ and a FEV1 $<80 \%$. Restrictive defect was defined as FVC $<80 \%$ with normal or increased FEV1/FVC.

Statistical analysis was performed by $\mathrm{IBM}^{\circledR} \mathrm{SPSS}^{\circledR}$ version 21 software. Correlation between variables in scale measure was studied by Pearson correlation coefficient. Mann-Whitney $U$-test and median test were applied to look for differences in the average between two independent groups. A $P$-value of $<0.05$ was defined as statistically significant.

\section{Results}

We identified 44 patients, followed in the UHP-HSM for SCD, who completed $17 \mathrm{yr}$ old in the last $10 \mathrm{yr}$. Twenty-four
$(55 \%)$ were female and $20(45 \%)$ were male. Forty three (98\%) were African descendants and 1 (2\%) was Caucasian. The median age at diagnosis was 10 months (min: $3 \mathrm{~d}$, max: $12 \mathrm{yr}$ and 5 months). Patients' hematological laboratory data are summarized in Table 1.

Beta-hemoglobin S haplotypes were characterized in 29 patients (66\%). The most common haplotype was Bantu/ Bantu in 16 cases, followed by Bantu/Benim in five cases and other less frequent haplotypes (Benim/Benim in three cases, Senegal/Senegal in two and Bantu/Senegal, Bantu/ Black two and Bebim/Senegal in one case each).

Alpha-thalassemia was present in 18 cases $(41 \%)$, caused by $-\alpha 3.7$ deletions in two alpha genes in 16 cases and in one alpha gene in seven cases.

The median number of hospital admissions during the follow-up period was 7 . Five patients $(11 \%)$ had no admissions, while nine patients (20\%) had 20-30 hospitalizations. The most frequent cause of admission was painful crisis (54\%), followed by infection (34\%), splenic sequestration and acute chest syndrome (3\% each), and less commonly aplastic crisis and leg ulcer (1.5\% each). Four patients (9\%) had dactylitis before their first birthday.

Chronic complications of SCD occurred in 35 patients (80\%), with a median of two complications per patient (Table 2). Of the 21 patients with slight dilation of left ventricle, seven presented a reduced ejection fraction, ranging from $30 \%$ to $49 \%$. No diastolic dysfunction was found. Of the 19 patients with respiratory function abnormalities, 15 had a restrictive defect, two had an obstructive defect, and two had both conditions. Six of the 18 patients with microlithiasis developed gallstones and were submitted to cholecystectomy during childhood. One of the 14 patients with increased flow velocity of cerebral arteries had a time-averaged mean of maximum velocity (TAMMV) higher than $200 \mathrm{~cm} / \mathrm{s}$, presenting a high risk of stroke. This patient and the one with recurrent priapism and persistent leg ulcer were submitted to transfusion therapy. Two other patients were treated with hydroxyurea, one due to recurrent episodes of acute chest syndrome and the other due to more than three admissions for painful crisis per year. There were no cases of renal dysfunction, stroke, or death in this series.

Table 1 Patients' hematological laboratory data

\begin{tabular}{llll}
\hline $\begin{array}{l}\text { Hematological } \\
\text { values }\end{array}$ & Mean & Minimum & Maximum \\
\hline $\begin{array}{l}\text { Steady-state } \\
\text { Hemoglobin } \\
\text { level }\end{array}$ & $8.0 \pm 0.9 \mathrm{~g} / \mathrm{dL}$ & $5.9 \mathrm{~g} / \mathrm{dL}$ & $9.7 \mathrm{~g} / \mathrm{dL}$ \\
$\begin{array}{l}\text { Fetal } \\
\text { Hemoglobin }\end{array}$ & $6.8 \pm 4.8 \%$ & $0.8 \%$ & \\
$\begin{array}{l}\text { Leukocyte } \\
\text { count }\end{array}$ & $12.95 \times$ & $6.6 \times 10^{3} / \mathrm{mm}^{3}$ & $21.9 \times 10^{3} / \mathrm{mm}^{3}$ \\
\hline
\end{tabular}


Table 2 Prevalence of chronic complications of SCD

\begin{tabular}{lc}
\hline Chronic complications & $\begin{array}{l}\text { Number of } \\
\text { affected } \\
\text { patients (\%) }\end{array}$ \\
\hline Slight dilatation of left ventricle & $21(47.7)$ \\
Respiratory function abnormalities & $19(43.2)$ \\
Microlithiasis/cholelithiasis & $18(40.9)$ \\
Increased flow velocity of cerebral arteries & $14(31.8)$ \\
Enuresis & $3(6.8)$ \\
Delayed puberty & $3(6.8)$ \\
Bone abnormalities & $3(6.8)$ \\
Proliferative retinopathy & $2(4.6)$ \\
Leg ulcer & $2(4.6)$ \\
Recurrent priapism & $1(2.3)$ \\
\hline
\end{tabular}

Leukocyte count above $15000 \times 10^{3} / \mathrm{mm}^{3}$ was found in 11 patients $(25 \%)$ and was significantly associated with a higher median number of admissions (20 vs. 5, Mann-Whitney $P<0.001)$ and chronic complications of the disease $(3$ vs. 1, Mann-Whitney $P=0.035$ ) (Fig. 1).

The steady-state basal hemoglobin was under $7 \mathrm{~g} / \mathrm{dL}$ in 4 patients $(9.1 \%$ ) and above $7 \mathrm{~g} / \mathrm{dL}$ in 40 patients $(90.9 \%)$. There was not a significant difference between these two groups regarding the median number of admissions (13.5 vs. 6, Mann-Whitney $P=0.512$ ), admissions for painful crisis (3 vs. $2, P=0.917$ ), or chronic complications of disease (2 vs. 2, Mann-Whitney $P=0.767$ ).

The percentage of $\mathrm{HbF}$ as a continuous covariate was not significantly related to the total number of hospital admissions ( $r_{\text {pearson }}=-0.277 P=0.069$ ) (Fig. 2), to the number of admissions for painful crisis $\left(r_{\text {pearson }}=-0.242\right.$ $P=0.113)$, or to the number of chronic complications ( $\left.r_{\text {pearson }}=-0.258 P=0.091\right)$.

The four patients who had dactylitis before their first birthday presented a significant higher median number of

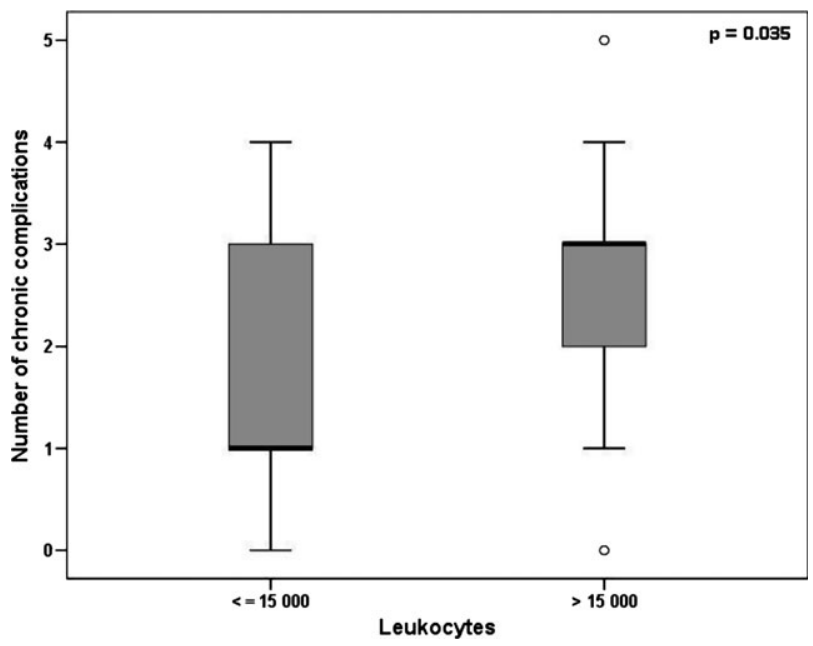

Figure 1 Association between leukocyte count and the number of chronic complications.

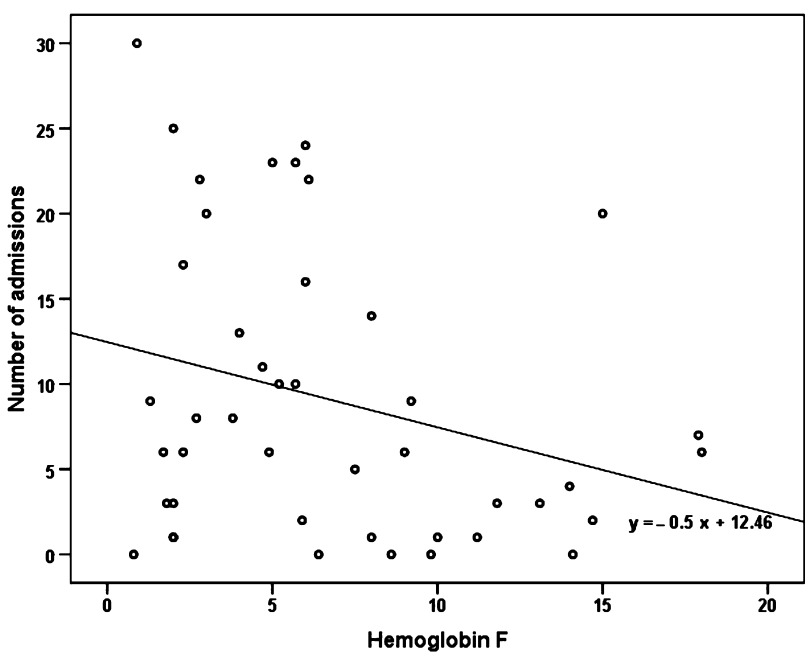

Figure 2 Distribution of the total number of admissions in function of $\mathrm{HbF}$.

hospital admissions (23 vs. 6, Mann-Whitney $P=0.004$ ) and chronic complications (3 vs. 1.5, Mann-Whitney $P=0.018$ ) (Fig. 3).

Patients with $\alpha$-thalassemia presented a significantly lower median number of chronic complications comparing with patients without thalassemia ( 1 vs. 3 , median test $P=0.036$ ) (Fig. 4) as well as a lower median number of hospital admissions (5 vs. 7.5, Mann-Whitney $P=0.811$ ).

\section{Discussion}

Sickle cell disease is a genetic disorder causing anemia and acute and chronic tissue damage in multiple organs. The survival of patients with SCD has steadily improved with the (i) institution of immunizations, prophylactic antibiotics, and

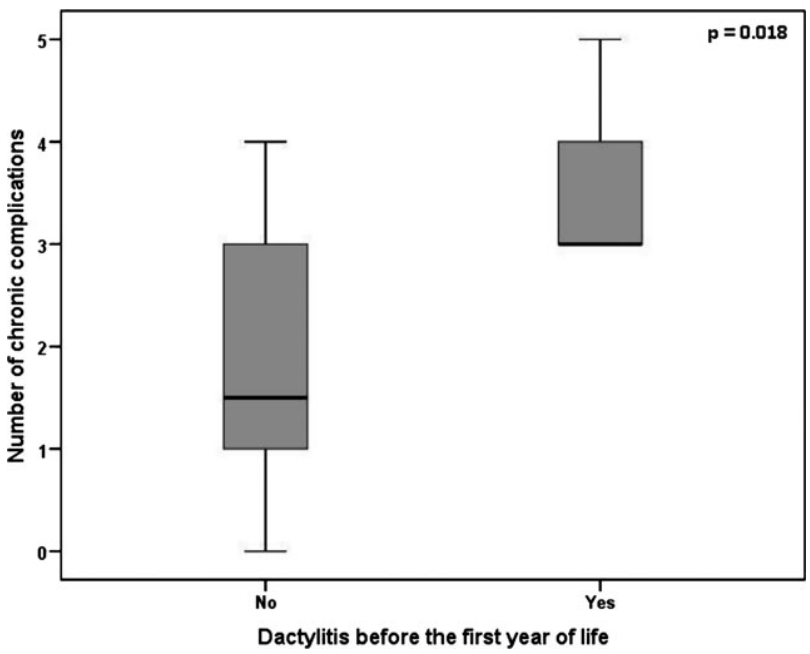

Figure 3 Association between the occurrence of dactylitis before the first year of life and the number of chronic complications. 


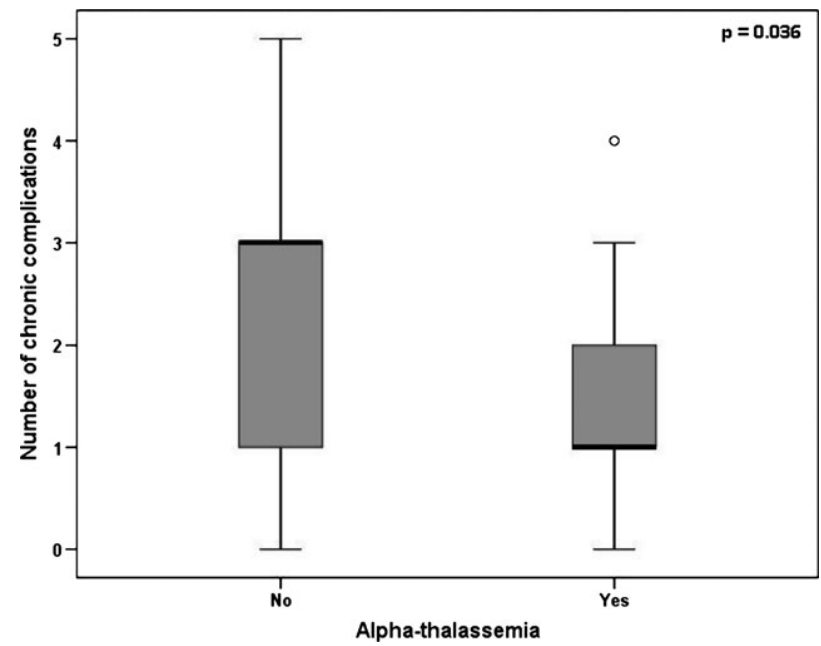

Figure 4 Association between the presence of $\alpha$-thalassemia and the number of chronic complications.

hydroxyurea; (ii) earlier diagnosis and treatment of disease complications; and (iii) improvement in patient education and comprehensive care $(4,8)$. Therefore, the disease has shifted from a fatal pediatric illness to a chronic condition associated with progressive deterioration of the organ function and quality of life $(4,8)$. In our study, most patients presented one or more chronic complications and no one died. These results reveal the tendency of the disease to a chronic multiorganic dysfunction and reinforce the need of periodic screening tests for possible complications as well as multidisciplinary approach of these patients through their life.

Cardiac exams findings are rarely normal in SCD (9). The heart is usually enlarged, and hyperactive precordium and systolic murmurs are found in most patients (9). This is well illustrated in our study, as almost half of the children $(47.7 \%)$ presented a slight dilatation of left ventricle. Evaluation of the pulmonary status in patients with SCD may reveal a variety of chronic manifestations including restrictive and obstructive lung disease, hypoxemia, and pulmonary hypertension, which may present separately or combined (8). Airway hyperreactivity occurs in nearly two-thirds of children with SCD (8). We found respiratory function abnormalities in $43.2 \%$ of patients, most of them (79\%) presenting a restrictive lung disease. Ultrasound surveys of patient populations indicate that the onset of cholelithiasis occurs as early as 2-4 yr old, and its prevalence progressively increases with age, affecting nearly $30 \%$ of patients until $18 \mathrm{yr}$ old (9). Microlithiasis was frequent in our patients $(40.9 \%)$ but only one-third of them developed cholelithiasis. Ischemic stroke can occur in at least $11 \%$ of patients with SCD by the age of $20 \mathrm{yr}$ old (10). High risk is associated with distal intracranial internal carotid (ICA) and proximal middle cerebral artery (MCA) stenosis which can be detected by transcranial doppler (10). This procedure is recommended for routine screening for stroke risk in children with SCD (11). The risk of stroke in children with high flow velocity in the ICA and MCA can be reduced with regular red cell transfusion, whose goal is to maintain hemoglobin $\mathrm{S}$ below $30 \%$ (10). An increased flow velocity of intracranial arteries was present in almost one-third of patients (32\%) but there were no cases of stroke. Other chronic complications as renal dysfunction, leg ulcer,and proliferative retinopathy ( 9 , 12, 13) are typically associated with an older age, which may explain the lower incidence of these complications in our series.

The patients with more symptomatic disease have a higher risk of early death, and the high frequency of acute painful episodes is a measure of clinical severity associated with a poor prognosis $(2,5,14)$. Therefore, we considered the number of admissions and chronic complications as markers of SCD's severity.

Although the role of leukocytes in the pathogenesis of SCD remains not completely clarified, leukocytes are known to be involved in the process of arterial occlusion and may be associated with the severity of the disease $(6,15)$. This is consistent with our results as we found a significant association between leukocyte count above $15000 \times 10^{3} / \mathrm{mm}^{3}$ and a higher number of hospitalizations and chronic complications of the disease.

In our report, the patients who had dactylitis in their first year of life presented a significant higher number of admissions and chronic complications comparing with the patients with no dactylitis in that period. This result reinforces the early onset of dactylitis as a predictive factor of disease severity.

The different beta-hemoglobin haplotypes have varying degrees of severity (4). Senegal haplotype has the least severe course of disease, probably due to the association with high levels of $\mathrm{HbF}$, while Bantu haplotype presents the lowest $\mathrm{HbF}$ levels and is related to a more severe disease (4). As we have a small sample of each haplotype, it was not possible to study the statistical association between the haplotypes and the number of complications or admissions in our patients.

The presence of $\alpha$-thalassemia is associated with a lower intraerythrocytic hemoglobin $S$ concentration within the microcytic red blood cells, which reduces polymerization of deoxyhemoglobin $\mathrm{S}$ and hemolysis. In our series, the presence of $\alpha$-thalassemia was significantly associated with a lower number of chronic complications. It was also associated with a lower number of hospital admissions, although with no statistical significance.

$\mathrm{HbF}$ level was described as the most straightforward laboratory risk factor for severe SCD (5). Several studies demonstrated that a higher level of $\mathrm{HbF}$ predicts a minor severity of the disease $(4,5,14)$ and that even moderate increases in the $\mathrm{HbF}$ level could reduce the pain rate (14). In our study, the percentage of $\mathrm{HbF}$ was not significantly related to the 
number of hospitalizations, admissions for painful crisis or number of chronic complications, contrary to what we expected. However, as we obtained a borderline $P$-value, these results are probably related to the small dimension of the sample, which is a limitation of our study.

The role of low hemoglobin level in the different complications of SCD can vary. A low hemoglobin level has previously been correlated with an increased risk of stroke and death in childhood $(5,6,15)$. On the other hand, higher hemoglobin levels correlate with increased risks of acute chest syndrome and painful crisis $(6,14,15)$. In our study, there was not a significant association between hemoglobin level and the number of total admissions, admissions for painful crisis or chronic complications of SCD.

Hydroxyurea is an antineoplastic agent that inhibits ribonucleotide reductase, increasing $\mathrm{HbF}$ within red blood cells (16). A double-blinded multicenter prospective pediatric trial about the use of hydroxyurea in very young children revealed its association with a significant (i) reduction in pain, dactylitis, acute chest syndrome, and need of hospitalization and transfusion and (ii) improvement in laboratory parameters (higher $\mathrm{Hb}$ and $\mathrm{HbF}$ and lower neutrophils count), with relative lack of toxicity (16). As hydroxyurea seems to be associated with a better quality of life and probably with a better long-term prognosis, it should be considered in the treatment of early age children with SCD, even in the absence of clinical symptoms (16).

Sickle cell disease is a chronic disease associated with a progressive deterioration in multiple organ function. This fact explains the need of periodic screening tests for possible complications and multidisciplinary approach for children with SCD. The determination of reliable early predictors of SCD severity would help to balance the risks between interventions and disease itself, providing an improvement in the comprehensive care of these patients. Leucocytosis and dactylitis in the early infancy can be predictors of SCD severity, while the presence of $\alpha$-thalassemia can be protective. More studies are needed to predict the individual risk of chronic complications of SCD, to optimize the follow-up and treatment of the disease.

\section{References}

1. Prevalence of rare diseases: Bibliographic data, Orphanet Report Series, Rare Diseases collection, Nov 2013, Number 1: Listed in alphabetical order of disease or group of diseases, http://www.orpha.net/orphacom/cahiers/docs/GB/Prevalence_of_rare diseases_by_alphabetical_list.pdf

2. Sebastiani P, Nolan VG, Baldwin CT, et al. A network model to predict the risk of death in sickle cell disease. Blood 2007; 100:2727-35.
3. Quinn CT, Shull EP, Ahmad N, Lee NJ, Rogers ZR, Buchanan GR. Prognostic significance of early vaso-occlusive complications in children with sickle cell anemia. Blood 2007;109:40-5.

4. Ogedegbe HO. Sickle cell disease: an overview. Lab Med 2002;33:515-43.

5. Platt OS, Brambilla DJ, Rosse WF, Milner PF, Castro O, Steinberg MH, Klug PP. Mortality in sickle cell disease. Life expectancy and risk factors for early death in sickle cell disease. N Engl J Med 1994;330:1639-44.

6. Miller ST, Sleeper LA, Pegelow CH, Enos LE, Wang WC, Weiner SJ, Wether DL, Smith J, Kinney TR. Prediction of adverse outcomes in children with sickle cell disease. $N$ Engl J Med 2000;342:83-9.

7. Foucan L, Ekouevi D, Etienne-Julan M, Salmi LR, Diara JP. Early onset dactylitis associated with the occurrence of severe events in children with sickle cell anaemia. The Paediatric Cohort of Guadeloupe (1984-99). Paediatr Perinat Epidemiol 2006;20:59-66.

8. Vichinsky EP. Overview of the clinical manifestations of sickle cell disease [UpToDate Web site]. November 2012. Available at: www.uptodate.com. Accessed April 2013.

9. National Institute of Health Publication. The Management of Sickle Cell Disease, 4th edn. Bethesda, USA: National Institute of Health Publication, 2002.

10. Jones A, Granger S, Brambilla D, Gallagher D, Vichinsky E, Woods G, Berman B, Roach S, Nichols F, Adams RJ. Can peak systolic velocities be used for prediction of stroke in sickle cell anemia? Pediatr Radiol 2005;35:66-72.

11. Lagunju I, Sodeinde O, Brown B, Akinbami F, Adedokun B. Transcranial doppler ultrasonography in children with sickle cell anemia: clinical and laboratory correlates for elevated blood flow velocities. J Clin Ultrasound 2014;42:8995.

12. Stallworth JR, Tripathi A, Jerrell JM. Prevalence, treatment, and outcomes of renal conditions in pediatric sickle cell disease. South Med J 2011;104:752-6.

13. Agência Nacional de Vigilância Sanitária. Manual de Diagnóstico e Tratamento de Doenças Falciformes, $1^{\mathrm{a}}$ edn. Brasília: Agência Nacional de Vigilância Sanitária, 2002.

14. Platt OS, Thorington BD, Brambilla DJ, Milner PF, Rosse WF, Vichinsky E, Kinney TR. Pain in sickle cell disease, rates and risk factors. $N$ Engl $\mathrm{J}$ Med 1991;325:11-6.

15. Quinn CT, Lee NJ, Shull EP, Ahmad N, Rogers ZR, Buchanan GR. Prediction of adverse outcomes in children with sickle cell anemia: a study of the Dallas Newborn Cohort. Blood 2008;111:544-8.

16. Wang WC, Ware RE, Miller ST, et al. A multicenter randomised controlled trial of hydroxyurea (hydroxycarbamide) in very young children with sickle cell anaemia. Lancet 2011;377:1663-72. 